\title{
Aprendizados: uma reflexão sobre os lugares da Antropologia da Educação na formação de cientistas sociais
}

\author{
Ceres Karam Brum ${ }^{1}$ \\ ${ }^{1}$ Universidade Federal de Santa Maria, Santa Maria, RS, Brasill
}

\section{Resumo}

Neste trabalho pretendo refletir sobre as potencialidades do ensino de Antropologia da Educação na formação de cientistas sociais na atualidade. Meu argumento de uma Antropologia como educação dialoga com o entendimento de Ingold $(2008 ; 2018)$ sobre a Antropologia como um processo educativo que envolve múltiplos aprendizados. Nesse sentido, proponho uma discussão sobre as características dos processos de ensino/aprendizagem e a formação de pesquisadores que se dão nos cursos de Ciências Sociais. A análise ocorrerá a partir de minha experiência como docente da disciplina de Antropologia da Educação, para os cursos de Licenciatura e Bacharelado em Ciências Sociais, e do Programa de PósGraduação em Ciências Sociais da Universidade Federal de Santa Maria (UFSM) - Rio Grande do Sul, Brasil, entre 2006 e 2021, tendo como contraponto minha também experiência de ensino de Antropologia da Educação para os cursos de Pedagogia e Educação Especial do Centro de Educação da UFSM. Esta discussão igualmente ocorrerá a partir de minha atuação como pesquisadora e orientadora de pesquisas em nível de graduação e pós-graduação em Antropologia da Educação.

Palavras-chave: Educação. Aprendizado. Ciências Sociais. Formação.

\section{Learning: a reflection on the places of the Anthropology of Education in the training of social scientists}

\begin{abstract}
In this work, I intend to reflect on the potential of teaching Anthropology of Education in the training of social scientists today. My argument for an anthropology as education dialogues with Ingold's (2008; 2018) understanding of anthropology as an educational process that involves multiple learnings. In this sense, I propose a discussion about the characteristics of the teaching/learning processes and the training of researchers that take place in Social Science courses. The analysis will take place from my experience as a professor of the subject of Anthropology of Education, for the Licentiate and Bachelor of Social Science courses, and the Postgraduate Program in Social Sciences at the Federal University of Santa Maria (UFSM) - Rio Grande do Sul, Brazil, between 2006 and 2021, having as a counterpoint my experience also teaching the Anthropology of Education for the Pedagogy and Special Education courses at the UFSM Education Center. This discussion will also take place from my work as a researcher and research advisor at the undergraduate and graduate level in Anthropology of Education.
\end{abstract}

Keywords: Education. Apprenticeship. Social Sciences. Formation. 


\section{Percursos e Memórias}

$\mathrm{N}^{\circ}$

o livro Anthropologie comme éducation, Tim Ingold (2018) desenvolve um amplo debate sobre as dimensões educativas da Antropologia. Grande parte do livro nos remete a um conjunto de conferências proferidas pelo autor na Université de la Bretagne, cujo tema Antropologia e educação é pensado em diálogo com o pensamento de John Dewey.

O debate a que se propõe remonta a momentos anteriores e perpassa boa parte da produção do autor Tim Ingold para quem, após exercer o métier de antropólogo por 50 anos e ensinar por pelo menos 40, a Antropologia não se reduz a um campo do conhecimento a estudar e ensinar, mas "a educação em sua constituição mesma" (INGOLD, 2018, p. 9). Ao abordar o cenário dos cursos de Antropologia em que ocorre a recepção do saber antropológico descrito nos manuais da disciplina, Ingold percebe, para além de um lugar de transmissão, um local criativo em que se rememora o saber dos predecessores, para se ir mais além, logo: um trabalho educativo desenvolvido com cumplicidade entre o autor/professor e seus estudantes. Mais do que isso, para Ingold, a Antropologia, no atual cenário universitário, pode inverter "as torres de ébano". Ela tem um papel emancipador (INGOLD, 2018, p. 93-94), uma vez que é capaz de mostrar as relações de poder subjacentes para as hierarquias tradicionais de saber e de questionar as razões universais e a objetividade empírica sobre as quais repousam.

Em um texto anterior, Ingold (2008) menciona a Antropologia como educação no contexto da distinção entre Antropologia e Etnografia. Efetua a crítica ao primado da etnografia como método e de suas distorções em relação ao fazer antropológico. Para o autor:

O que realmente distingue a antropologia [...] não é um estudo do todo, mas um estudo com (sic). Antropólogos trabalham e estudam com as pessoas. Imersos no seu ambiente de atividade conjunta, eles aprendem a ver as coisas (ou ouvi-las ou tocá-las) e, nesse sentido, eles são seus professores e companheiros. Uma educação em antropologia, portanto, faz mais do que fornecer-nos o conhecimento sobre o mundo - sobre as pessoas e suas sociedades. É algo que educa a nossa percepção do mundo e abre os nossos olhos e mentes para outras possibilidades de ser. (INGOLD, 2008, p. 82)

A segunda proposição de Ingold, alguns anos antes, me conduziu a um primeiro questionamento sobre o ensinar/fazer antropológico na atualidade, dos quais os principais resultados, em diálogo com Suzana Cavalheiro de Jesus, foram divulgados em Brum e Jesus $(2018)^{1}$. Naquele momento, não se tratava propriamente do trabalho de campo e

Trata-se do artigo "Antropologia como educação: um diálogo sobre experiências de ensino da antropologia em cursos de formação de professores e seus desafios", publicado em 2018 pela Revista em Ciências Sociais da Unisinos. 
de seus impasses (conforme a segunda proposição de Ingold), mas dos investimentos e reflexões que, como educadoras, realizamos em termos dos significados de aprender Antropologia - exatamente o que o autor desenvolve no seu livro L'anthropologie comme éducation (2018).

É nessa perspectiva, levando em consideração um possível extrapolar dos já bastante intrincados processos de transmissão do saber antropológico, na formação de cientistas sociais, e de questionamentos sobre os possíveis lugares de uma reflexão sobre uma educação para a Antropologia, nos cursos de formação de professores no Brasil, que gostaria de refletir sobre o que denomino de aprendizados.

Tentarei desenvolver esta reflexão a partir de um percurso singular. O do meu próprio estranhamento e encontro com o espinhoso problema da formação de antropólogos/ cientistas sociais que vem perpassando minha trajetória de formação e atuação profissional na UFSM, onde atuo há 16 anos como docente/pesquisadora.

A Universidade Federal de Santa Maria, concebida em 1960, inaugurou a interiorização do ensino superior no Sul do Brasil. Santa Maria está situada no centro do Rio Grande do Sul. De acordo com o Instituto Brasileiro de Geografia e Estatística (IBGE), em 2019, Santa Maria possuía 282.123 habitantes. É considerada uma cidade médio porte e de grande influência na região central do estado, especialmente em termos educacionais, já que congrega, além da UFSM, vários outros centros universitários e faculdades.

Meu encontro com Santa Maria e a UFSM ocorreu na década de 1980, mais precisamente em 1987, quando ingressei no curso de Ciências Jurídicas e Sociais. Permaneci na UFSM até 1999, cursando também Licenciatura em História e os Mestrados em Educação e Integração Latino-Americana. Meu retorno a Santa Maria ocorreu em 2005, após a conclusão do doutorado em Antropologia Social pela Universidade Federal do Rio Grande do Sul, para ingressar como docente no Departamento de Fundamentos da Educação, do Centro de Educação da UFSM.

Penso que algumas palavras sobre a minha formação em Antropologia são importantes. Contar uma história, no dizer de Ingold (2018, p. 25), possui uma função educativa não pelo conteúdo narrado, transmitido por um código de informações que o narrar engendra, mas pela significação encontrada por quem a escuta, que estabelece correspondência com suas experiências e história de vida.

Se isso é verdadeiro, ao narrar como me "tornei antropóloga", desejo reencontrar os traços do sentido dessa escolha que se fez tardiamente e que se refletem em minha prática docente e em percepções do campo de conhecimento antropológico. Talvez esse narrar possa ecoar também nos corações e mentes daqueles que, como eu, partiram de outros campos do conhecimento e que foram de alguma forma seduzidos pela antropologia, seus legados e possiblidades.

Meus primeiros contatos com a Antropologia se deram pelas bordas. Como mencionei anteriormente, não possuo graduação em Ciências Sociais. Cursei uma disciplina de Antropologia Cultural na Licenciatura em História e foi seguindo suas pistas que desejei cursar um doutorado em Antropologia Social, no qual tudo era novo para mim. Em alguns anos de aprendizado formal, tangenciei a teoria antropológica clássica e contemporânea, antropologias específicas, pesquisa de campo e, como de praxe, concluí esse ciclo com a apresentação de uma etnografia. Tive colegas muito generosos, excelentes professores 
e um orientador que superou todas as minhas expectativas, com quem tive e continuo tendo muito a aprender e a trocar. Fizemos inclusive trabalho de campo juntos, como parte desse processo educativo ${ }^{2}$.

Apesar do entusiasmo mencionado, reconheço que foi um processo sofrido. Eu não me sentia segura. Tinha medo de expressar minhas opiniões em sala de aula, vergonha de dizer, besteira embora todos tentassem me estimular a falar. O campo foi sempre uma espécie de terapia para minhas incertezas e meu melhor aprendizado. Eu me sentia tão perto dos informantes, parecia entender o que diziam e queriam me ensinar. Estava com eles e penetrava em seus mundos. Isso me estimulou a refletir e me propiciou segurança para me construir como antropóloga.

O final do doutorado, com a defesa da tese, deixou um vazio e a saudade de minha primeira experiência no exterior - o doutorado sanduíche, a vida na Maison du Brésil de Paris ${ }^{3}$. Com sua conclusão por meio do rito de passagem de tornar-me antropóloga (no meu caso com a defesa da tese), veio a pressão de encontrar um trabalho, passar em um concurso, investir em ser professor/pesquisador. A oportunidade se concretizou exatos seis meses depois em um concurso para professor no Departamento de Fundamentos da Educação em que investi, já durante o processo seletivo, nas relações entre a Antropologia, a História e a Educação $0^{4}$.

Analisando minha trajetória formativa e as opções de trabalho, que apresento a seguir, percebo que tal trajetória se enquadra no perfil descrito por Oliveira (2017). O autor, no artigo "Uma Antropologia fora do lugar? Um olhar sobre os antropólogos na educação", se refere a antropólogos que sofreram processos de conversão à Antropologia (OLIVEIRA, 2017, p. 245). Baseado na classificação de Sanabria (2005, p. 88-89), ele menciona três sinais inequívocos para sua identificação, quais sejam: 1) a aquisição de um olhar antropológico; 2) a análise antropológica vinculada à capacidade de relativizar o próprio ponto de vista; e 3) a fala e a escrita qualificadas. Para Oliveira (2017), tais sinais se reverteriam em "marcas de conversão", que se reverteriam na sua atuação, ocasionando:

Essas "marcas de conversão" possivelmente se fariam presentes no modo como tais profissionais passariam a perceber o objeto educacional a partir da formação acadêmica adquirida na antropologia. Esse grupo acaba, portanto, por visibilizar uma dada compreensão acerca das finalidades e potencialidades da

\footnotetext{
Destaco, nesse sentido, a coorganização do livro "Expressões da cultura gaúcha" com Ruben George Oliven e Maria Eunice de Souza Maciel, lançado em 2010 pela editora da UFSM.

3 Muito marcante nesse processo foi o estágio de doutorado no exterior, com a experiência de pensar a construção de identidades regionais no Brasil a partir do estágio em Paris. O diálogo com Anne-Marie Thiesse da École des Hautes Études em Sciences Sociales e École Normale Superieur (que supervisionou a pesquisa) foi fundamental para o estreitamento de laços entre a antropologia, a história e a educação nas pesquisas sobre identidade regional e nacional. Destaco, nesse sentido, sua participação no Dossiê "Antropologia da Educação" que organizei para a Revista Educação da UFSM em 2009, com o artigo "Ensinar a nação pela região: o exemplo da terceira república francesa (THIESSE, 2009, p. 13-27).

4 Oliveira (2017, p. 233) se refere às dificuldades de mapeamento de uma Antropologia da Educação no Brasil, destacando a pulverização disciplinar dos docentes pesquisadores entre diversos departamentos nas universidades e a quase ausência de trabalhos nesse sentido. Ele propõe como recorte para esta análise a atuação nos programas de pós-graduação em educação, por meio dos dados coletados na Plataforma Sucupira e Plataforma Lattes. Segundo o autor, tais dados possibilitam: "[...] realizar reflexões mais amplas não apenas sobre o lugar da educação na agenda de pesquisa da antropologia, mas sim sobre qual o lugar da antropologia na pesquisa educacional brasileira" (OLIVEIRA, 2017, p. 325).
} 
antropologia, uma vez que a passagem de um campo teórico e epistemológico para outro não se dá sem dissonâncias. Parece haver aí uma compreensão de que a antropologia poderia oferecer chaves analíticas relevantes às discussões travadas no campo educacional, ou ainda que através de suas ferramentas metodológicas ela possibilitaria outras aproximações com o objeto de investigação. (OLIVEIRA, 2017, p. 246)

Iniciei meu trabalho na UFSM em dezembro de 2005, após uma longa greve que nos obrigou a permanecer em sala de aula até fevereiro de 2006. Desse primeiro semestre, recordo a carência que percebi ao trabalhar com as disciplinas de História, Filosofia e Sociologia da Educação, ofertadas para os cursos de Pedagogia e Educação Especial e, mesmo nos Projetos Políticos Pedagógicos (PPCs) desses dois cursos, de uma discussão mais antropológica sobre educação. Sentia falta de uma reflexão que extrapolasse e se contrapusesse a algumas propostas que considerava fragmentadas inspiradas nos Estudos Culturais, que discutiam, por exemplo, cultura dos surdos e inclusão escolar sem levar em consideração a perspectiva desses sujeitos e suas opiniões.

Como sugere Gusmão (2008), ao analisar as relações entre Antropologia, Estudos Culturais e Educação os debates sobre cultura são centrais nas análises contemporâneas sobre educação. Um de seus problemas, porém, se cinge ao entendimento e às representações que se tem da Antropologia e da atuação dos antropólogos para além de seus muros. Aqueles que se definem como praticantes dos Estudos Culturais - se é que é possível pensarmos em sua configuração no Brasil no dizer de Ortiz (2004, p. 123) - criticam a Antropologia como uma ciência eternamente marcada por sua origem colonialista, sem levar em consideração a história da disciplina e suas possibilidades teórico-metodológicas, na esteira da proposta de Tosta e Rocha (2009).

Apesar das dificuldades encontradas, de ser uma voz solitária da Antropologia e de suas potencialidades, no Centro de Educação da UFSM, em que os professores/ pesquisadores possuíam outras opções para pensar cultura escolar, o ano de 2006 foi animador em termos das relações entre Antropologia e educação. Havia um conjunto de debates que vinham se processando em nível nacional dentro e fora dos cursos de pedagogia e que, naquele momento, alcançaram o Centro de Educação da UFSM por meio de uma proposta de reforma do PPC do curso de Pedagogia que, sem dúvida, decorreu da publicação da Resolução CNE/CP n. 1, de 15 de maio de 2006, que instituiu as diretrizes curriculares nacionais para o curso de graduação em Pedagogia, licenciatura, ampliando a atuação do pedagogo, conforme estabelece o seu artigo $2^{\circ}$ :

Art. $2^{\circ}$ As Diretrizes Curriculares para o curso de Pedagogia aplicam-se à formação inicial para o exercício da docência na Educação Infantil e nos anos iniciais do Ensino Fundamental, nos cursos de Ensino Médio, na modalidade Normal, e em cursos de Educação Profissional na área de serviços e apoio escolar, bem como em outras áreas nas quais sejam previstos conhecimentos pedagógicos. (BRASIL, 2006, p. 1)

A Resolução CNE/CP n. 1, de 15 de maio de 2006, ampliou a atuação do pedagogo para espaços não escolares voltados para a docência, como em hospitais e nas escolas indígenas $\left(\operatorname{artigo} 5^{\circ}, \S 1^{\circ}\right.$ ), por exemplo. Essa ampliação implicou igualmente a alteração do corpus teórico metodológico e prático do curso, passando a Antropologia a fazer parte 
dos já clássicos Fundamentos da Educação (História, Sociologia, Filosofia e Psicologia). Assim, a Resolução passou a estabelecer um conjunto de modificações na formação dos pedagogos, como o previsto nos incisos I e II do seu $\S 2^{\circ}$ :

O curso de Pedagogia, por meio de estudos teórico-práticos, investigação e reflexão crítica, propiciará:

I - o planejamento, execução e avaliação de atividades educativas;

II - a aplicação ao campo da educação, de contribuições, entre outras, de conhecimentos como o filosófico, o histórico, o antropológico, o ambientalecológico, o psicológico, o lingüístico, o sociológico, o político, o econômico, o cultural. (BRASIL, 2006, p. 2)

Foi nessa perspectiva que propus a criação da disciplina de Antropologia da Educação para se somar aos demais fundamentos da educação, conforme ementa que apresento a seguir:

\begin{abstract}
Antropologia da Educação
EMENTA: Concepções e objetivos do ensino da Antropologia Social, suas inter-relações com as demais ciências sociais e sua especificidade teórico-metodológica. A Antropologia da Educação. Cultura, identidade e educação. Abordagem antropológica da cultura escolar, a partir de uma perspectiva multicultural abrangendo a discussão das questões de gênero, etnicidade, sexualidade, na construção da nação brasileira, em relação às suas peculiaridades regionais. Antropologia da criança. A educação como sistema simbólico, memórias, histórias, mitos e ritos referentes aos processos de ensino e aprendizagem. O relativismo e o etnocentrismo nas sociedades contemporâneas, no contexto educacional.
\end{abstract}

Apesar dos esforços do próprio Departamento de Fundamentos de Educação que votou pela aceitação da proposta, ela não foi aceita pela comissão que coordenava a reformulação do Projeto Político Pedagógico do Curso de Pedagogia, alegando a impossibilidade da implementação da disciplina em virtude da quase inexistência de docentes habilitados. O fato de ser a única antropóloga do Centro de Educação da UFSM pesou negativamente com relação à proposta e nem mesmo a perspectiva iminente do financiamento do REUNI foi suficiente para modificar a situação.

Em razão dessa negativa, as disciplinas de Antropologia da Educação e de Antropologia Aplicada à Educação Especial (para o curso de Educação Especial) foram concebidas como Disciplinas Complementares de Graduação (DCGs). Ao longo dos anos de 2006 e 2009, elas foram oferecidas a ambos os cursos. Igualmente concebi uma disciplina para o curso de Especialização em Gestão Educacional, denominada Antropologia da Educação e Gestão Educacional, que ministrei durante os anos de 2008 e $2009^{5}$.

Meu objetivo com a concepção da Antropologia da Educação e, consequentemente, da criação de uma área ainda não existente na UFSM foi alavancar uma discussão sobre as possibilidades teóricas, metodológicas e temáticas da relação educação/antropologia no contexto da formação de professores. Nesse sentido, a disciplina foi configurada

Esta busca de um espaço de desenvolvimento da Antropologia da Educação no Centro de Educação resultou em um conjunto de interlocuções com pesquisadores de outras instituições de ensino superior, a participação em eventos nos GTs de Antropologia da Educação, bem como a organização do Dossiê Antropologia da Educação e sua publicação pela a Revista do Centro de Educação UFSM. 
de forma bem panorâmica cujo objetivo central era trabalhar com alguns conceitos antropológicos elementares, mas capazes de informar sobre a antropologia como campo de conhecimento e suas potencialidades de reflexão sobre a diversidade cultural e os processos educacionais, para além dos cenários de escolarização.

Rememorando o percurso desse processo de criação, é preciso reconhecer que a proposta era ambiciosa no sentido de configurar um novo campo disciplinar em um cenário bem demarcado historicamente. Apesar de uma legislação que conferia o aporte legal da proposta, ao exigir a ampliação da área de fundamentos da educação, reconhecendo a importância das discussões da Antropologia na formação de pedagogos, o campo acadêmico, em suas configurações e articulações, foi refratário à proposta.

Neusa Gusmão (2016, p. 63), ao retomar a análise das relações entre antropologia e educação e a necessária centralidade das discussões sobre cultura nos cursos de formação de professores no Brasil, exemplifica acerca de alguns impasses. Ressalta que a obrigatoriedade da legislação que inclui as discussões sobre diversidade étnica no Brasil (Lei n. 11.645/2008) nos currículos escolares não é suficiente para garantir o avanço em termos da superação do racismo, apontando a necessidade de preparação do professor para implementá-la. Ao concordar com a autora, olhando a experiência vivida do reconhecimento da Antropologia como um dos fundamentos da educação (CNE/CP n. 1/2006) e de sua negativa de aceitação pelo CE/UFSM, saliento que temáticas curriculares e a inclusão de novas disciplinas em um PPPC devem "fazer sentido" não apenas para quem ensina, mas para os professores que queremos formar.

Nessa perspectiva, desejo começar a destacar alguns aprendizados resultantes da concepção e trabalho com as disciplinas de Antropologia da Educação no CE/UFSM. Um duplo aprendizado que me acompanhou nesse processo do "fracasso" da tentativa de implantação da Antropologia da Educação no Centro de Educação da UFSM: por um lado a percepção de que o ensino de Antropologia tem de estar conectado com suas possibilidades de pesquisa, o tempo do estranhamento, da realização de trabalho de campo e do reconhecimento de sua legitimidade na construção de conhecimento sobre educação e sobre a escola, entre outras questões - impossível em um ambiente dominado pelos estudos culturais. Por outro lado, percebi que a Antropologia da Educação auxilia na superação das dificuldades dos estudantes de se colocarem ativamente, de estabelecerem conexões em relação às temáticas discutidas sobre cultura em outras disciplinas formadoras da Pedagogia e da Educação Especial. Para Gusmão (2016), vale afirmar a necessidade de discutir a escola a partir de um enfoque antropológico como fundamental na formação de professores:

Na Antropologia, vista como Antropologia da Educação na formação de professores que querem ser também educadores, defende-se a necessidade de considerar a bagagem cultural do aluno e do professor, suas mentalidades em confronto e em interação com conteúdo formal e informal de aprendizagem, postas em contexto, vale dizer, no espaço social e datado em que se inserem, no qual vivem. Por esse meio, contribui-se diretamente com o processo educativo, pois não há um afastamento do campo educacional, mas compreende-se tal campo de modo total e integrado, como parte de um contexto social e político determinado, do qual também se é - professores e alunos - parte integrante. Supera-se, assim, o risco da redução da educação e do processo educativo à 
escola e à ação educativa de natureza instrumental e ideológica. Caminha-se para além da escola e pode-se, então, recuperar a dimensão da cultura presente em diferentes mentalidades para entendê-la como processo e movimento no pano de fundo da história. (GUSMÃO, 2016, p. 64-65)

O delinear do lugar da Antropologia da Educação no percurso da formação de professores, apresentado por Gusmão (2016), se conecta com uma percepção apresentada por Ingold (2018, p. 37), para quem a educação encontra no habitar o mundo, chave para sua compreensão. Nessa percepção se valorizam processos não formais em que a agência do sujeito que aprende se transforma ao longo da ação ela mesma. Esse aprendizado é situacional, conforme nos ensina Jean Lave (2015, p. 39), e se baseia em um processo individuado de educação da atenção (INGOLD, 2010). Aprender é significado como situação vivida e introjetada como experiência.

No relato mencionado acima, relativo ao meu percurso na UFSM, em que desejei ensinar Antropologia da Educação, com o objetivo de estimular as reflexões dos professores em formação sobre educação como produção cultural e busca de alteridade, aprendi com a sala de aula e com a burocracia universitária experienciando cotidianamente os limites formais de um campo em construção, em suas potencialidades latentes. Uma educação forjada com a experiência de docência e de pesquisa.

E foi no fio da navalha entre o reconhecimento da necessidade formativa da Antropologia da Educação e sua recusa no CE/UFSM que prossegui, já que nesse mesmo momento se descortinava, em razão do projeto REUNI na UFSM e demais políticas públicas correlacionadas, outra possibilidade de diálogo: a criação do curso de Licenciatura em Sociologia e a estruturação do Programa de Pós-Graduação em Ciências Sociais no Departamento de Ciências Sociais. Nosso diálogo remonta à minha chegada na UFSM, quando ministrei a disciplina de História da Educação para uma turma criada para habilitar os egressos do bacharelado em Ciências Sociais, da UFSM à docência de Sociologia na educação básica, seguindo a exigência legal instituída pela Lei n. 11.684, de 2 de junho de 2008, que altera o artigo 36 da LDB/1996, incluindo a Sociologia e a Filosofia como disciplinas obrigatórias nos currículos do ensino médio.

A criação do curso de Licenciatura em Sociologia foi um processo demorado e negociado na instituição, especialmente entre a Pró-Reitoria de Graduação, o Centro de Educação e o Centro de Ciências Sociais e Humanas, ao qual se vincula o Departamento de Ciências Sociais. O motivo principal se cingiu à distribuição de vagas docentes e ao monopólio dos cursos de formação de professores exercido pelo Centro de Educação. O Projeto Pedagógico do Curso (PPC) de Licenciatura em Sociologia foi o resultado final dessa barganha por vagas docentes, com acomodação das disputas entre os departamentos, frente às particularidades necessárias para a formação de professores de Ciências Sociais, como indicado em trabalhos anteriores (BRUM; PERURENA; OLIVEIRA, 2014).

O PPC respeitou as configurações de campo já mencionadas de uma pretensa divisão de poderes e saberes acadêmicos em que o Centro de Educação, por meio de seus departamentos, concorria com as disciplinas didático-pedagógicas necessárias para a formação de professores e o Departamento de Ciências Sociais com as disciplinas teóricometodológicas atinentes às Ciências Sociais. A exceção a essa divisão se processou com 
duas disciplinas que ficaram lotadas no DCS: a Antropologia da Educação e a Sociologia da Educação.

A vinculação de ambas as disciplinas ao DCS se configurou em um importante diferencial do curso de Licenciatura em Sociologia em que, como consequência, parte da discussão sobre formação de professores de Sociologia passou a ser capitaneada por Cientistas Sociais de formação. Insisto sobre a importância dessa abertura na formação de licenciados para atuação no ensino médio, pois: situar a educação como tema caro às Ciências Sociais, em suas particularidades, resultou do reconhecimento que cientistas sociais tinham algo a dizer sobre ser professor, para além e em diálogo com o quadro das disciplinas ofertadas pelos demais departamentos que compunham o curso.

Nessa esteira, as reflexões sobre ensino de ciências sociais e formação de professores, desde a concepção do curso, estiveram atreladas ao Departamento de Ciências Sociais, embora boa parte do quadro docente não possuísse qualquer formação ou afinidade com as reflexões da licenciatura. A disciplina de Antropologia da Educação e minha própria inserção como docente, a partir de abril de 2009, ficaram vinculadas ao Departamento de Ciências Sociais. O terceiro aprendizado que destaco se inscreve nesta perspectiva: a discussão sobre formação de professores em Ciências Sociais deve obrigatoriamente incluir cientistas sociais. Esse, no meu entendimento, é um dos problemas corporificado pelo modelo $3+1$, que se caracteriza pela separação entre a formação de bacharéis em Ciências Sociais e as adaptações didático-pedagógicas que conferem posteriormente o título de licenciado em Ciências Sociais, que deve ser ultrapassado.

Como corolário, a Antropologia da Educação na UFSM, que nasceu no Centro de Educação, com o objetivo de fundamentar a formação de educadores especiais e pedagogos passou a se configurar e a se projetar como campo disciplinar vinculado às Ciências Sociais e a seus cursos de bacharelado, licenciatura e ao Programa de Pós-Graduação em Ciências Sociais. A disciplina de Antropologia da Educação vem sendo oferecida anualmente como disciplina obrigatória para o curso de Licenciatura em Sociologia (que a partir de 2013 passou a ser denominado Licenciatura em Ciências Sociais) e como Disciplina Complementar de Graduação (DCG) para o curso de Bacharelado em Ciências Sociais.

Nesse sentido, a disciplina foi amplamente reconfigurada. Sua nova proposição, ao fomentar o diálogo entre a Antropologia e a Educação extrapolou a apresentação dos conceitos antropológicos e a justificação de sua aplicabilidade na formação de pedagogos/ educadores especiais e problemas de pesquisa. Sua ambição, tanto na graduação como na pós-graduação em Ciências Sociais, passou a se cingir à constituição de um campo na Antropologia para pensar a educação como um problema de pesquisa e de ação caro aos cientistas sociais e, especialmente, aos antropólogos/antropólogos da educação estreitamente relacionada ao estudo da cultura. 


\section{A Antropologia da Educação no Curso de Licenciatura em Ciências Sociais da UFSM}

Revisitar esses anos de trabalho de concepção e desenvolvimento de Antropologia da Educação no Departamento de Ciências Socais da UFSM não é tarefa fácil, sobretudo pelo conjunto de aprendizados propiciados ao longo desse processo que vem dialogando com os objetivos da formação de professores de Ciências Sociais entre 2008 e 2020. Exemplo disso foi a radical modificação na legislação que ensejou a criação do curso de Licenciatura em Sociologia (PPPC, 2009) (Lei n. 11.648/2008 que tornou obrigatória a Sociologia e a Filosofia no ensino médio) em relação à reforma do ensino médio (Lei 13.415/2017) e à Base Nacional Comum Curricular. Destaco ainda a reforma curricular pela qual passou o curso em 2013, ocorrida após a primeira avaliação do Ministério da Educação (nota 4), que acarretou a modificação do nome do curso, mais adaptado à formação de professores em ciências sociais, bem como as reformas a que vêm sendo submetidos os cursos de licenciatura (2015-...). O curso de Licenciatura em Ciências Sociais/UFSM voltou a ser avaliado pelo MEC em 2018, obtendo nota 5.

A Antropologia da Educação, já presente no PPPC de Licenciatura em Sociologia, continua a fazer parte do PPPC de Licenciatura em Ciências Sociais no $5^{\circ}$ semestre de curso, juntamente com a Sociologia da Educação com o objetivo, conforme já salientado, de estimular as reflexões atinentes à educação como campo de estudo caro às Ciências Sociais e à formação de professores. Além disso, tal configuração curricular tem como objetivo efetuar a diferenciação da educação como problema sociológico, antropológico e suas interfaces.

A educação como corolário da cultura, em suas configurações, ocupa lugar central nas discussões de Antropologia da Educação. A disciplina se constitui como uma antropologia especial para discutir educação como cultura (BRANDÃO, 2002), aprendizagem, cultura escolar, métodos e configurações do campo, conforme objetivos e programa a seguir:

ISP1080 ANTROPOLOGIA DA EDUCAÇÃO (4-0)

OBJETIVOS: ao término da disciplina o aluno deverá ser capaz de: Refletir sobre algumas matrizes do conhecimento antropológico - como as noções de cultura, identidade, aprendizagem, gênero, etnicidade, diferença e diversidade cultural, etnocentrismo, relativismo e multiculturalismo - relativamente ao contexto educacional e escolar brasileiro, em que atuará como cientista social e educador. Abordar os temas diversos relacionados à inclusão escolar, educação indígena, ciências sociais no ensino médio em suas particularidades no Brasil, incluindo a análise das políticas públicas e da legislação.

PROGRAMA: TÍTULO E DISCRIMINAÇÃO DAS UNIDADES

UNIDADE 1 - ANTROPOLOGIA

1.1 - Por que estudar Antropologia da Educação em um curso de Licenciatura em Ciências Sociais?

1.2 - A Antropologia Social e a Educação interfaces e desafios.

1.3 - A Antropologia na Educação e a Educação na Antropologia.

1.4 - A antropologia da Educação como campo de conhecimento: caracterização mundial e brasileira. 
1.5 - A especificidade da prática antropológica, o trabalho de campo e a etnografia.

1.6 - Etnografia da Educação.

UNIDADE 2 - CULTURA E EDUCAÇÃO

2.1 - Cultura, conhecimento, educação e aprendizagem.

2.2 - Os conceitos de cultura e civilização para a Antropologia da Educação.

2.3 - A Cultura escolar.

2.4 - Cultura e Identidade. Conceitos e interfaces nos processos educacionais formais e informais.

2.5 - Relativismo, etnocentrismo e educação. Os PCNs e o respeito à diferença cultural.

UNIDADE 3 - CULTURA ESCOLAR

3.1 - Criança, juventude e ritos escolares.

3.2 - Estigma, Inclusão, exclusão e aprendizagem.

3.3 - As Ciências Sociais no Ensino Médio. Escola, ensino e docência.

3.4 - Etnicidade e educação.

3.5 - Ações afirmativas no Brasil e o seu impacto na educação superior.

3.6 - Gênero, sexualidade, família, violência e educação.

A atual configuração do programa da disciplina já atende às exigências da reforma das Licenciaturas $^{6}$, que vem sendo debatida na UFSM desde 2015. O ensino da Antropologia da Educação na Licenciatura em Ciências Sociais que objetiva potencializar a discussão da educação como um dos campos de estudo da Antropologia, ao dialogar com as demais antropologias presentes no PPPC, enfoca a história da Antropologia Social e Cultural como campos de conhecimento no que concerne à educação em seus desenvolvimentos específicos. As relações entre Antropologia e Educação são discutidas em escala mundial (ANDERSON-LEVITT, 2006) e brasileira (GOMES; GOMES, 2012) com o intuito de caracterizar não apenas sua especificidade da área em diferentes contextos históricos e geográficos, mas o movimento contínuo e dinâmico desses processos. A Antropologia da Educação é trabalhada como um campo em construção e pleno de disputas, especialmente as relativas aos embates teóricos, metodológicos e epistêmicos que caracterizam as relações entre a Antropologia e os Estudos culturais, ao enfocar a educação como uma ciência de serviço (GUSMÃO, 2008).

No Brasil, tal fato adquire dimensões epistemológicas importantes, pois permite que os estudantes percebam que os processos de construção de identidades nacional e regionais no Brasil são problemas educacionais de amplas dimensões. O tratamento historicamente dado ao racismo, que vem sendo invisibilizado ao longo do processo histórico brasileiro, por meio da ideologia da mestiçagem (MUNANGA, 2003), e as transformações relativas à educação indígena, às cotas sociais e raciais nas universidades brasileiras, que ocupam um espaço considerável nos estudos da nossa Antropologia da Educação, são bons exemplos das potencialidades desse trabalho na formação de professores de Ciências Sociais, entre outros.

C Conforme preconizado na Resolução CNE/CP n. 2/2015. Diário Oficial da União, Brasília, Seção 1, p. 8-12, em 2 de julho de 2015. 
As discussões metodológicas ocupam um lugar importante ao longo da disciplina e têm por intuito desenvolver reflexões sobre as potencialidades da etnografia como método de investigação na escola, conforme propõem Amurabi Oliveira (2013) e Rockwell (2009), bem como o compromisso de uma vigilância metodológica proposta por Fonseca (1998). Fundamentalmente, a antropologia da educação deseja se apresentar como um espaço possível de estudo e pesquisa de processos de transmissão cultural, sejam eles formais ou não. Da necessidade de se relativizar, conforme aponta Manuela Carneiro da Cunha (2009b), o conhecimento científico como uma das formas de conhecer o mundo, mas não a única.

É nesse sentido que o investimento em reflexões sobre cultura, aprendizagem e educação é central na disciplina. De um lado, essas reflexões permitem aproximar a educação da cultura como um processo humano que acompanha nossa passagem pelo planeta, como ressalta Brandão (2002). Processos de habitar o mundo, como preconiza Michel Serres (2001), se relacionam à aprendizagem como viagem e marcha dinâmica.

Aqui está o preceito em resposta, mas não tire nada do corpo nu. Consequentemente, ele retém apenas seu treinamento, sua própria força, sua flexibilidade, suas capacidades, seu despertar adaptativo, sua linguagem, sua cultura, sua ciência: nada disso pesa nem vê; vá com o mais leve, isto é, o que você pode ou o que você sabe: isso é suficiente; então aprenda a sair. Pare de aprender. [...] E para sempre aprender, é sair. A bagagem mais leve não conta, não é visível, não pesa, pois o corpo a assimila [...] Viver tem como raiz e origem o verbo ter; quem viaja não tem nada; aqui está, então, bem estar. A palavra pedagogia significa esta jornada e o aprendizado eleva-se ensinandose que se pode zombar de ter. (SERRES, 2001, p. 6-7, tradução nossa) ${ }^{7}$

Essa aventura descrita como habitar o mundo é a própria definição de educação mencionada por Ingold (2008) já destacada. Na Antropologia da Educação, a aprendizagem é deslocada de sua dimensão biológica (de mais ou melhor aparelhados para aprender) como decorrente de um processo de acumulação de representações, conforme preconizam os cognitivistas, para um investimento em suas dimensões situacionais que valorizam o sujeito em sua relação ecológica com o contexto desse aprendizado. Assim, aprendemos com a desconstrução dos estereótipos, de uma aprendizagem baseada na superação de estigmas como no concernente às percepções sobre a educação dos portadores de altas e baixas habilidades. Buscamos alternativas mais humanas valorizadoras de suas vivências, conforme propõe Ricardo Ross (1999).

Os processos de avaliação são processuais e contínuos, incentivando os estudantes a interpretarem e a criarem a partir das leituras dos textos propostos por mim e de temáticas escolhidas por eles, em aproximação com suas experiências de pesquisa, o que provoca muitas vezes desconforto e inquietação, porque o campo é ainda visto como algo mitificado e ritualizado. Essa ênfase na pesquisa e na escrita como aprendizados me levou

\footnotetext{
Do original: Voici donc le prècepte en réponse, encore n'emmenez rien de ce qui difere du corps nu. Par conséquent ne garde que son entrainement, sa force propre, sa souplesse, ses capacités, son éveil adaptatif, sa langue, sa culture, sa science: rien de cela ni pèse ni ne ce voit; pars avec le plus lèger, c'est à dire ce que tu peux ou ce que tu sais: cela suffit; apprends donc pour quitter. Quitter pour apprendre. [...] Et apprendre toujours, consiste à partir. Le plus léger bagage ne compte pas, ne se voit pas, ne pèse pas, puisque le corps l'assimila [...] Habiter a pour racine et origine le verb avoir; celui qui voyage n'a plus rien; le voici alors bien force d'être. Le mot pédagogie signifie ce voyage et l'apprendissage élève l'être en l'enseigmant qu'on peut se moquer d'avoir (SERRES, 200l, p. 6-7).
} 
à concepção de uma disciplina complementar de Graduação, denominada Etnografia e Educação, e ao diálogo com a disciplina Ciências Sociais para o Ensino Médio (que extrapolam os limites deste texto).

Como aprendizados dessa experiência em curso e que se renova a cada semestre letivo, nesse cenário de fricção e de diálogo com estudantes e colegas de instituição, destaco a sensibilidade para a leitura de novos contextos formativos caracterizados por uma constante mudança de legislação e por processos de desumanização dos professores e da cultura escolar, corporificados em projetos como a Escola sem Partido. "Uma andorinha só não faz verão", como diz o ditado popular. A formação de professores é um projeto coletivo descrito nos PPPCs e vivido por meio de múltiplas atividades de ensino, pesquisa e extensão dentro e fora da universidade. Se posso falar em êxito no processo formativo na Antropologia da Educação, esse aprendizado se deu em função de um cenário de diálogo favorável com outras disciplinas e entre graduação e pós-graduação.

\title{
3 Notas sobre a Formação de Antropólogos no Programa de Pós-Graduação em Ciências Sociais da UFSM
}

No que concerne a um investimento nas discussões a respeito de ensino/aprendizagem nos PPGs de Antropologia no Brasil, Oliveira (2017) efetua uma análise destacando a quase inexistência de um debate a respeito de educação:

\begin{abstract}
Atualmente, [entre] os 24 programas de pós-graduação em antropologia que há no Brasil, apenas um possui uma linha de pesquisa explicitamente conectada com o debate educacional (Oliveira, A., 2015). Porém isso não significa que não haja antropólogos que se tenham dedicado à pesquisa educacional em diversos programas de pós-graduação, ou que não haja a elaboração de dissertações e teses voltadas para este debate; com relação aos pesquisadores é importante destacar que eles se encontram relativamente dispersos em alguns programas (Oliveira; Boin; Búrigo, 2016). (OLIVEIRA, 2017, p. 239)
\end{abstract}

Essa mesma realidade é, de certa forma, confirmada por Tosta, Maia e Silva (2020, p. 11) com relação aos PPGs de áreas afins na sua pesquisa, que se estendeu também para o que consideram áreas híbridas:

Para além dos Programas de Pós-graduação em Antropologia (PPGAs), é comum, no Brasil, programas híbridos que promovem a interface entre Sociologia e Cultura, História e Cultura, Sociologia e Antropologia etc. Nestes casos, a decisão foi a de buscar nesses outros programas as dissertações e teses que tematizaram educação/escola na linha de tempo definida pela investigação e cujos orientadores tivessem sido antropólogos. Acreditamos que, assim, não fugiríamos da questão central que norteou a pesquisa e sua abrangência. (TOSTA; MAIA; SILVA, 2020, p. 11)

Como primeiras conclusões, os autores apontam que:

[...] apesar de a produção acadêmica na área de Antropologia em diálogo com a Educação\Escola ter se intensificado nos últimos anos no Brasil, é necessária uma maior mobilização de pesquisadores e institutos de pesquisa em termos de um maior investimento nessa modalidade de investigação. (TOSTA; MAIA; SILVA, 2020, p. 14) 
Apesar desse cenário, Oliveira (2017, p. 249) destaca a presença e a atuação dos pesquisadores nos PPGCS. Observo que é nesse contexto em que se insere o Programa de Pós-Graduação em Ciências Sociais da UFSM.

O programa foi criado em 2008, no Departamento de Ciências Sociais, com a participação de professores dos campos de Sociologia, Ciência Política e Antropologia. Nosso desafio desde o começo do funcionamento do mestrado foi promover uma articulação interdisciplinar entre as três áreas, preservando ao mesmo tempo sua autonomia. Nesse sentido, a proposta de pesquisa e ensino em Antropologia da Educação foi bem recebida e articulada na linha de pesquisa Identidades Sociais e Etnicidade, que passou a se denominar Identidades Sociais, Etnicidade e Educação desde 2015, valorizando o interesse de pesquisas na área de cultura/aprendizagem/educação nas Ciências Sociais ao longo dos 13 anos de funcionamento do PPGCS/UFSM. Até o presente momento foram desenvolvidas 16 pesquisas de mestrado que, em sua totalidade, apresentam interfaces com a Antropologia da Educação, além de três orientações de doutorado em andamento. Apresento a seguir a relação de trabalhos de doutorado relacionados à Antropologia da Educação:

1) Renata Colbeich da Silva. Entrelaçando memória, antropologia e educação: etnografia e produção de conhecimentos de intelectuais indígenas em formação na UNIPAMPA. Início: 2019. Tese (Doutorado em ciências sociais) - Universidade Federal de Santa Maria, Coordenação de Aperfeiçoamento de Pessoal de Nível Superior. Orientador: Ceres Karam Brum.

2) Fernanda Stoher Barbosa. Epistemes ameríndias na Universidade: a criação da disciplina Danças de Matrizes Indígenas no Curso de Dança Licenciatura UFSM. Início 2020. Tese (Doutorado em ciências sociais) - Universidade Federal de Santa Maria, Orientador: Ceres Karam Brum.

3) Amanda Silveira. Cor, corpo, coletivo: o movimento negro universitário vinculado à graduação em dança no Rio Grande do Sul. Início 2020. Tese (Doutorado em ciências sociais) - Universidade Federal de Santa Maria. Orientador: Ceres Karam Brum.

4) Gabriela Franz. Interseccionalidades da epistemologia da criança: interação, percepção e imaginação na cultura de pares Início 2021. Tese (Doutorado em ciências sociais) - Universidade Federal de Santa Maria. Orientador: Ceres Karam Brum.

No Programa de Pós-graduação em Ciências Sociais, a Disciplina de Antropologia \& Educação ${ }^{8}$ vem sendo anualmente ofertada como disciplina optativa, tendo como principal objetivo colocar em diálogo os temas de pesquisas das dissertações, em processo de produção, com os autores e temáticas da Antropologia da Educação.

\footnotetext{
8 A nomenclatura das disciplinas que trabalham as relações entre Antropologia e Educação no DCS/PPGCS acompanha a tendência latino-americana dominante na atualidade (GUSMÃO, 2018) ao entender a educação como objeto de estudo da Antropologia, como outras Antropologias específicas (Antropologia da Saúde e Antropologia do Desenvolvimento, por exemplo). O nome Antropologia \& Educação se deve a já existência de uma Antropologia da Educação nos cursos de licenciatura e bacharelado em Ciências Sociais, daí a escolha da nova nomenclatura para fins de identificação no quadro institucional, buscando evitar confusões no quadro da burocracia universitária. Vale assinalar que, a partir de 2019, o PPGCS começou a ofertar as disciplinas também para o curso de doutorado.
} 
Nesse sentido, há uma intencionalidade na desconstrução do sinônimo educação/ escolarização e sua aproximação do conceito de cultura (BRANDÃO, 1989; 2002) como processo partilhado e perpassado por múltiplos aprendizados (GOMES; LUCE; DEBORTOLI, 2010). Aí reside uma das dimensões da Antropologia como prática educativa, na perspectiva de Ingold (2018, p. 77), da qual a disciplina se apropria de forma consciente.

De uma forma mais aprofundada e problematizada do que na graduação, os estudantes, ao longo da disciplina, que se inicia com um panorama sobre a configuração atual da Antropologia da Educação no Brasil e no mundo (GOMES; GOMES, 2012; ANDERSON-LEVITT, 2006), são interrogados constantemente sobre as dimensões dos aprendizados presentes em suas temáticas de pesquisa, bem como sobre as potencialidades da etnografia como possibilidade epistemológica de construção de uma antropologia "com". Desenvolvemos também discussões sobre uma pluralidade de processos educacionais, bem como um revisitar e atualizar os conceitos de cultura, identidade, etnocentrismo e relativismo cultural em relação, por exemplo, às temáticas da criança, da escola, de gênero, de sexualidade, de juventude, de nação, de região, de violência, de etnicidade, etc. com o intuito de produzir um constante estranhamento de mundo, algumas hipóteses de interpretação e, ainda, alguma pista de ação nesses cenários educacionais em mundos habitados, conforme refere Ingold (2018). O entendimento de disciplina se aproxima do de território determinado por fronteiras do conhecimento que possuem uma arquitetura interior, mas que deve constantemente ser tencionado e dialogar com a arquitetura exterior da universidade (INGOLD, 2018, p. 92).

Por fim, a questão das reflexões sobre docência, da formação de professores de ciências sociais em diferentes níveis, se apresenta como contraponto necessário no cenário de cultura escolar em que a disciplina e o campo se inscrevem. A incorporação dessa discussão, por um lado, se deu em virtude de um dar-se conta das possibilidades de trabalho dos cientistas sociais, mesmo bacharéis, especialmente nas universidades. Por outro lado, a percepção de uma carência efetiva nos cursos de pós-graduação no Brasil de uma discussão sobre a problemática da docência, de sua invisibilidade curricular nos PPGs, frente à obrigatoriedade dos estágios docentes dos mestrandos e doutorandos imposta pela CAPES e CNPq a seus bolsistas.

A seguir apresento as perspectivas de quatro pesquisadoras de mestrado da turma de 2013, na atividade de autoavaliação da disciplina de Antropologia \& Educação para situar sua recepção e significados em sua formação:

Uma disciplina que não era de minha linha de pesquisa, mas que desde o início me interessou bastante. Estava sentindo falta do debate sobre educação, sobre escola, sobre crianças. Acredito que aqui encontrei o que faltava. Pensando em todas as aulas que tivemos, concluo que foi uma disciplina prazerosa. As aulas fluiam, os assuntos debatidos eram interessantes e provocavam muitas discussões. O único problema foi o tempo, ou melhor, a configuração, a limitação de tempo que nos era imposta. Não pela professora, mas por todo o sistema. Aquele era o tempo da aula, mas as reflexões certamente não se moldavam apenas ali, persistiam em outros espaços. Todos os debates realizados sempre me provocaram a pensar em algo relacionado ao meu projeto ou a pesquisas futuras que me interessam bastante! (Fernanda, 2013)

Dessa forma, aprender a etnografia na umbanda envolveu o treinamento da percepção para construir de forma mais precisa o meu objeto de estudo como a articulação entre corpo e mente 
nas técnicas umbandistas de incorporação. Esse objeto tem como pano de fundo a educação nas dimensões do que venho discutindo nesse trabalho, mas antes, prescinde de uma definição e descrição detalhada. (Helaysa, 2013)

A opção pela escolha dessa disciplina no mestrado, inicialmente com a temática ferroviários e religião, não me pareciam estar muito relacionadas, mas visando o meu interesse pela disciplina escolhi cursá-la no mestrado. No decorrer da disciplina já percebi maneiras de interrelacionar os textos com a temática de pesquisa, quando fiz a mudança de tema, o uso dos textos ficou cada vez mais nítido [...] Obrigada, prof. Ceres por compartilhar e transmitir o seu conhecimento de maneira agradável e atrativa, fazendo com que a aula de quarta fosse a nossa a busca pelo conhecimento de maneira leve, mas com muito mais interesse do corpo discente. Diferenciando-se das outras disciplinas as quais eram cansativas, nos fugia a concentração e o interesse em cada aula. (Trícia, 2013)

A disciplina Antropologia e Educação foi muito interessante para minha experiência pessoal e para meu trabalho acadêmico, através dela tive a oportunidade de conhecer antropólogos e pensadores que ainda não conhecia como: Tim Ingold, Ana Gomes, Elsie Rockwell entre outros. Também pude compreender melhor essa relação dos estudos antropológicos com a área da educação que até então não tinha tido contato. (Kézia, 2013)

A pluralidade temática das dissertações, teses e demais pesquisas relacionadas à Antropologia da Educação que tenho orientado e desenvolvido na UFSM é o resultado não apenas de uma abertura pessoal para o desafio de um caminho plural de pesquisa e ação, abraçado com meus orientados, que nos fez transitar da questão da educação indígena à discussão de identidades nacionais, regionais e etnicidade, passando pelo Movimento dos Sem Terra, depredação do patrimônio escolar, educação prisional, casa de estudante (BRUM, 2014), jogos, religião, ensino de sociologia/filosofia, aprendizagem, epistemologia e violência nos "processos formais de escolarização".

Sobretudo, essa pluralidade se relaciona com uma aposta no ensino e com a configuração da Antropologia da Educação (graduação) e Antropologia \& Educação (pós-graduação) e de uma antropologia da ação (BRUM; JESUS, 2018), em que a desconstrução dos limites da educação como campo é uma constante, conforme as falas acima demonstram. Por seu turno, meu percurso na UFSM com o ensino e a orientação de pesquisas em Antropologia da Educação, a concepção das disciplinas para graduação e pós-graduação e mesmo minha atuação como gestora e tutora do Pet indígena da UFSM, entre 2011 e 2015, bem como na qualidade de gestora (fui coordenadora do curso de Licenciatura em Sociologia/Ciências Sociais entre 2011-2016) igualmente incitou minha curiosidade sobre a situação da Antropologia da Educação em outros espaços formativos de graduação e pós-graduação. Na busca de um diálogo com os demais cursos de PósGraduação em Ciências Socais e de Antropologia no Brasil, pois efetuei uma incursão no Portal da CAPES, com o seguinte questionamento: nos PPGCS no Brasil, como se configura o ensino de Antropologia/Antropologia da Educação?

Dos 23 programas consultados na área de Ciências Sociais, a grande maioria não apresenta disciplinas e/ou informações nesse sentido. Não encontrei nenhuma disciplina designada Antropologia da Educação/Antropologia \& Educação nos seus quadros. No entanto, me deparei com algumas disciplinas relacionadas. Na Universidade Federal de Uberlândia: "Educação nas Ciências Sociais"; "Educação, cultura e cidadania" e "Ensino de Sociologia"; na Universidade Estadual de Londrina: "Sociologia do conhecimento escolar; Pressupostos para análise das disciplinas e os currículos" e "Os jovens e o saber: 
fundamentos sócio-antropológicos da noção da relação com o saber"; na PUCRIO, a disciplina de "Cultura, Jovens e Novas Sensibilidades"; e na Universidade Federal do Rio Grande do Norte, a existência de um Programa de Pós-Graduação denominado Sociedade e Educação (doutorado/mestrado). A consulta nos Programas de Antropologia efetuada no Portal da Capes mostrou um panorama similar e desanimador.

No entanto, como referi anteriormente, todos os programas de pós-graduação têm como exigência de seus bolsistas a realização de estágio docente na graduação sem haver uma preparação ou discussão nesse sentido. É preciso refletir sobre as contradições dessa "pretensa espontaneidade", por meio de um olhar que denuncie a transformação que as universidades sofreram ao longo dos três séculos de sua história para reinventá-las como espaço educativo em que a Antropologia tem papel fundamental. Para Ingold (2018, p. 93, tradução nossa):

Como outras instituições públicas, as universidades oferecem alvos fáceis para o mercantilismo. Mas não há evidências de que os regimes de gestão que se arrogaram a atividade de controle do que eles chamam de "setor" (o "não" que eles dão ao que se tornou um mercado global lucrativo) medem bem as questões. Sua visão de curto prazo do ensino superior é limitada a índices de produtividade e índices brutos. O ensino é indexado à satisfação e empregabilidade do aluno, pesquisa sobre inovação e potencial comercial. Estes critérios nada têm a ver com a educação democrática e estão prestes a replicar a economia do conhecimento, com o enfraquecimento dos direitos civis e as desigualdades inerentes. A missão educacional, da qual as universidades herdaram o Iluminismo, sobrevive apenas na teoria de hoje? .

As digressões de Ingold fornecem um quadro que nos possibilita dialogar com a estrutura de ensino e pesquisa da pós-graduação no Brasil, em seus rígidos limites e perspectivas. A imposição do estágio nesse cenário exemplifica uma realidade no mínimo questionável e desejável de ser transformada, em que não apenas a universidade deve redefinir seus objetivos, mas também a educação deve ser restituída a universidade.

A configuração da cultura escolar para Perez Gomez (2001) se inscreve em um conjunto de interfaces, conflitos e contradições a que concorrem e interagem saberes, estrutura do campo científico e do conhecimento, de poderes políticos, econômicos e jurídicos, as "culturas" dos grupos envolvidos nesse diálogo e disputas, suas dimensões epistêmicas, apenas para citar alguns elementos dessa dinâmica em constante transformação que ocorre também na cultura universitária.

Os programas de pós-graduação em Ciências Sociais no Brasil se caracterizam por uma formação/especialização "em conjunto e em diálogo" com a Sociologia e a Ciência Política. Cabe salientar que a formação se dá em termos da organização de disciplinas voltadas para a especialização, que se comunicam com a dissertação de mestrado/tese de doutorado.

\footnotetext{
No original: À l'instar d'autres instituitions publiques, des universités offrent des cibles faciles pour le mercntilisme. Mais rien ne prouve que les régimes de gestion qui se sont arrogé l'activité de controle de ce qu'ils appellent "le secteur"(le non qu'ils donnent a ce qu'il est devenu un marché mondial lucratif) mesurent bien les enjeux. Leur vision à court term de la éducation superieur se limite à des índices bruts de rang et de productivité. L'enseigment est indexé sur la satisfaction et capacite d'insertion professionnelle des étudiants, la recherché sur l'innovation et le potential commercial. Ces critères n'ont rien à voir avec l'éducation démocratique et sont sur le point de reproduire l'économie du savoir, avec l'affaiblissement de droits civiques et des inegalités inhérentes. La mission educative, don't les universités ont hérite des Lumières survit aujour'hui en théorie uniquiment (INGOLD, 2018, p. 93).
} 
Nesse sentido, é preciso reconhecer que produzimos no Brasil uma cultura universitária que nos encerra em malhas disciplinares pouco maleáveis e que, de alguma forma, invisibiliza questões fundamentais nesses processos, cujo melhor exemplo é a questão do ensino, especialmente em espaços de pós-graduação. Formamos cientistas sociais/antropólogos sem que tenhamos um espaço no contexto de nossos programas de pós-graduação para pensar sobre sua formação, sobre a dupla dimensão pesquisador/ professor e suas implicações.

Nossas instituições de fomento impõem aos programas de pós-graduação a obrigatoriedade de nossos estudantes realizarem estágios como docentes, sem oferecer qualquer formação/reflexão nesse sentido. Essa ausência de reflexão e/ou sua invisibilização nos coloca como corolário alguns questionamentos para pensar os processos de ensino/ aprendizagem que me parecem extremamente importantes e que mexem com as fronteiras disciplinares da Antropologia e com as representações que possuímos da disciplina, desde seu interior como professores formadores, bem como de suas representações exteriores, conforme sugerem DaMatta (1987) e Fonseca (1998).

A falta de preparo e a ausência de um diálogo sobre como ensinar soam como mais um dos desafios de uma cultura classificatória e meritocrática da universidade que é altamente formalizada e ritualizada e que silencia "não por acaso" sobre questões fundamentais. Essa situação demonstra que a representação que temos da docência é algo menor, que os obstáculos colocados nos processos de aprendizagem formal são espontaneamente superados pelos fortes, porque eles possuem domínio de conteúdo e isso seria o suficiente no mundo acadêmico.

Rosana Pinheiro-Machado (2016), ao discutir sobre vaidade como uma característica da vida acadêmica, menciona a classificação entre "fracos" e "fodas" para trabalhar as representações distorcidas que produzimos sobre fracasso e sucesso na vida acadêmica e seus consequentes adoecimentos:

Os seminários e as exposições orais são marcados pela performance: coloca-se a mão no queixo, descabela-se um pouco, olha-se para cima, faz-se um silêncio charmoso acompanhado por um impactante "ãaaahhh", que geralmente termina com um "enfim" (que não era, de fato, um "enfim"). Muitos alunos se sentem oprimidos nesse contexto de pouca objetividade da sala de aula. Eles acreditam na genialidade daqueles alunos que dominaram a técnica da exposição de conceitos. (PINHEIRO-MACHADO, 2016)

A discussão da autora é sintomática do adoecimento que vivemos na universidade brasileira e, para mim, diz muito sobre os processos de aprendizado e sobre o que acreditamos por formação, sobretudo nos cursos de formação de professores de Ciências Sociais, cuja escolha como área de atuação pressupõe o reconhecimento de sua tripla dimensão de ocupação, vocação e profissão, de quadros institucionais e disciplinares organizados nesse sentido, de investimentos e disposições individuais e coletivas para esse aprendizado, que se inscrevem em um cenário, por vezes, pouco oxigenado da cultura universitária. O ensino de Antropologia e as problematizações que decorrem do ensino de Antropologia da Educação são importantes nesse processo formativo tripartido.

Por seu turno, a aquisição do conhecimento antropológico nos cursos de Ciências Sociais, em termos da formação de antropólogos, se dá de uma forma igualmente 
espontânea, já que grande parte do aprendizado da Antropologia ocorre no contexto dos trabalhos de campo como parte e inter-relacionados com esses processos de pesquisa, conforme ensina Ingold (2008). O autor destaca também esse caráter espontâneo do aprendizado do campo e critica o pouco tempo que dispensamos para ensinar essa dimensão da Antropologia, como processo educativo, já que passamos a maior parte do tempo em sala de aula a repetir teorias e a contar a história da antropologia (INGOLD, 2008).

\section{Considerações Finais}

Ao longo deste texto, tentei apresentar alguns contornos acerca da formação de antropólogos e de como as disciplinas de Antropologia da Educação e Antropologia \& Educação tentam dialogar com esse processo na UFSM. De como foi possível concebêlas e desenvolvê-las em um campo de disputas de poderes e saberes. Nesse processo, a questão dos desafios, os significados e as características da formação em Antropologia na esteira de Fonseca (1998) foram parceiros, especialmente porque meu percurso foi desenvolvido de "fora para dentro" das Ciências Sociais, impondo constantemente o repensar sobre a utilização da etnografia em pesquisas educacionais por não cientistas sociais.

Esse descolamento e a deturpação da etnografia, mencionados por Fonseca, é igualmente criticado por Ingold (2008), que, por sua vez, propõe uma Antropologia em que prática e teoria se comunicam incessantemente, de forma situacional. Em que a Antropologia passa a se constituir em um processo educacional de amplo espectro que descentra e transforma visões de mundo e suas percepções éticas.

Sua perspectiva de uma Antropologia como educação perpassada por múltiplos aprendizados, que nomeia este texto, vem fortalecendo meu desejo de reflexão e de atuação sobre a formação de professores nos cursos de Ciências Sociais e tem me levado a interrogar igualmente sobre os processos de ensino/aprendizagem em seus contornos individuais e coletivos.

Lave (2015, p. 38) aborda a aprendizagem para além dos seus limites de um processo cognitivo e individual. Para ela, a aprendizagem é um fenômeno fundamental do qual o ensino pode ou não ser parte e que adquire principalmente a dimensão de produção de identidade, nos projetos de vida dos participantes em comunidades.

A dimensão disciplinar na Antropologia certamente nos impõe muitos desafios e fronteiras para o aprendizado. Um deles é o de imprimir espontaneidade e liberdade com reflexidade na sua formação. Um processo do desenvolvimento de skills (habilidades) que se processa a partir do trabalho de campo, corporificado em uma educação da atenção (INGOLD, 2010), para a diferença e sua interpretação. Outro importante desafio que certamente acompanha nossa tarefa de formadores é a do encantamento: de uma sedução para a descoberta de cenários culturais sem descuidar dos aprendizados sobre a responsabilidade ética e política da tarefa de interpretação e de atuação a ser realizada pelos antropólogos da educação que estamos formando.

Para além dos desafios da profissionalização e da precarização do mercado de trabalho, é necessário não perder a dimensão da educação como corolário da produção cultural 
humana, para recuperar seu sentido antropológico. A Antropologia da Educação pareceme uma boa perspectiva de abordagem, um espaço privilegiado para essa recuperação da dimensão educativa da universidade. Finalizo a escrita deste texto com o desejo de continuar trilhando esse caminho no trabalho como docente/pesquisadora.

\section{Referências}

ANDERSON-LEVITT, Kathryn M. Les divers courants en anthropologie de l'éducation. Dossier Anthropologie de l'éducation, pour un tour du monde. Éducation et Societé, [s.l.], n. 17, p. 7-27, 2006. https://doi.org/10.3917/es.017.07

BRANDÃO, C. Rodrigues. O que é educação. São Paulo: Ática, 1989. (Coleção Primeiros Passos)

BRANDÃO, C. Rodrigues. A educação como cultura. Campinas: Mercado das Letras, 2002.

BRASIL. Lei n. 11.684, de 2 de junho de 2008. Disponível em: http://www.planalto.gov.br/ ccivil_03/_Ato2007-2010/2008/Lei/L1 1684.htm. Acesso em: 15 jun. 2014.

BRASIL. Resolução CNE/CP n. 1, de 15 de maio de 2006. Disponível em: http://portal.mec. gov.br/cne/arquivos/pdf/rcp01_06.pdfDOU. Acesso em: 7 jun. 2014.

BRUM, Ceres karam. (org.). Dossiê de Antropologia da Educação. Educação, [s.l.], v. 34, n. l, jan.-abr. 2009.

BRUM, Ceres karam. (org.) Dossiê Educação Indígena: abordagem antropológica. Revista Século XXI, [s.l.], nov. 2013. Disponível em: http://cascavel.ufsm.br/revistas/ojs-2.2.2/index. php/seculoxxi/issue/view/623. Acesso em: 30 maio 2018.

BRUM, Ceres karam. Programa de Antropologia da Educação: PPC Curso de Licenciatura em Ciências Sociais. Santa Maria, RS, UFSM, 2014.

BRUM, Ceres karam. Programa da disciplina de Antropologia \& Educação: Disciplina Optativa para Mestrado em Ciências Sociais, 2013/2.

BRUM, Ceres karam. Maison du Brésil: um território brasileiro em Paris. Porto Alegre: Evangraf, 2014.

BRUM, Ceres. K.; PERURENA, Fátima C. V.; OLIVEIRA, Rubia. M. A construção e a implantação dos cursos de Licenciatura em Sociologia na UFSM. Saberes em Perspectiva, [s.l.], v. 4, p. 51, 2014.

BRUM, C. K.; JESUS, Suzana C. Mito, diversidade cultural e educação: notas sobre a invisibilidade guarani no Rio Grande do Sul e algumas estratégias nativas de superação.

Revista Horizontes Antropológicos, Porto Alegre, n. 44, Dossiê Cultura e Aprendizagem, p.201-227, 2015.

BRUM, C. K.; JESUS, Suzana C. Antropologia como educação: um diálogo sobre experiências de ensino da antropologia em cursos de formação de professores e seus desafios. Ciências Sociais Unisinos, [s.l.], v. 54, p. 217-228, 2018.

CARVALHO DA ROCHA, A. L.; ECKHERT, C. Etnografia: saberes e práticas. Porto Alegre: Iluninuras, 2011.

CUNHA, Manuela C. Relações e dimensões entre saberes tradicionais e saberes científicos. In: CUNHA, Manuela C. Cultura com aspas. São Paulo: Cosac Naify, 2009a. p. 301-310.

CUNHA, Manuela C. Cultura e culturas: conhecimentos tradicionais e direitos intelectuais. In: CUNHA, Manuela C. Cultura com aspas. São Paulo: Cosac Naify, 2009b. p. 311-373. 
DAMATTA, Roberto. Relativizando: uma introdução à Antropologia Social. Rio de Janeiro: Rocco, 1987.

FONSECA, Claudia. Quando cada caso NÃO é um caso: pesquisa etnográfica e educação. In: XXI REUNIÃO ANUAL DA ANPED, Caxambu, setembro de 1998. Anais [...]. Caxambu, 1998. Disponível em: http://www.anped.org.br/rbe/rbedigital/RBDE10/RBDE10_06_CLAUDIA_ FONSECA.pdf. Acesso em: 10 abr. 2019.

GOMES, Ana; LUCE, Patrícia C.; DEBORTOLI, J. Experiência, Performance e Práticas de Aprendizagem. Licere, Belo Horizonte, v. 13, n. 2, jun. 2010. 26p.

GOMES, Ana; GOMES, Nilma Lino. Anthropology and education in Brazil: possible pathways. In: ANDERSON-LEVITT, Kathryn M. Anthropologies of education: a global guide of ethnographic studies of learning and schooling. Brooklyn NY: Berghahn Books, 2012. p. 111 130.

GUSMÃO, Neusa M. M. Antropologia, estudos culturais e educação: desafios da modernidade. Proposições, Campinas, v. 19, n. 3 (57), p.47-82, set.-dez. 2008.

GUSMÃO, Neusa M. M. Antropologia, Cultura e Educação na Formação de Professores. Revista Anthropológicas, Ano 20, v. 27, n. 1, p. 45-71, 2016. Disponível em: http://www. revista.ufpe.br/revistaanthropologicas/index.php/revista/article/view/688/425. Acesso em: 29 maio 2019.

IBGE - INSTITUTO BRASILEIRO DE GEOGRAFIA E ESTATÍSTICA. [2019]. Disponível em: https:/www.ibge.gov.br/cidades-e-estados/rs/santa-maria.html. Acesso em: 9 ago. 2020.

INGOLD, Tim. Anthropology is not ethnography. British Academy, [s.l.], 2008. Disponível em: http://proc.britac.ac.uk/tfiles/154p069.pdf. Acesso em: 30 jul. 2019.

INGOLD, Tim. Da transmissão de representações à educação da atenção. Educação, Porto Alegre, v. 33, n. 1, p. 6-25, jan.-abr. 2010.

INGOLD, Tim. O dédalo e o labirinto: caminhar, imaginar e educar a atenção. Revista Horizontes Antropológicos, Porto Alegre, n 44, Dossiê Cultura e Aprendizagem, p. 21-36, 2015.

INGOLD, Tim. L'anhropologie comme éducation. Rennes: Presses Universitaires de Rennes, 2018.

JULIA, D. A cultura escolar como objeto histórico. Revista de História da Educação, Campinas, 2001.

LAVE, Jean. Aprendizagem como/na prática. Revista Horizontes Antropológicos, Porto Alegre, n. 44, Dossiê Cultura e Aprendizagem, p. 37-47, 2015.

MUNANGA, Cabengele. Algumas considerações sobre a diversidade e a identidade negra no Brasil. In: MUNANGA, Cabengele. Diversidade e Educação: reflexões e experiências. [Brasília, DF]: MEC, 2003. p. 35-50.

OLIVEIRA, Amurabi. Por que Etnografia no sentido Estrito e não Estudos do Tipo Etnográfico em Educação? Revista FAEEBA, [s.l.], v. 22, p. 69-82, 2013. Disponível em: https://www. revistas.uneb.br/index.php/faeeba/article/viewFile/751/524. Acesso em: 20 ago. 2019.

OLIVEIRA, Amurabi. Uma antropologia fora do lugar. Horizontes Antropológicos, Porto Alegre, ano 23, n. 49, p. 233-253, set.-dez. 2017.

OLIVEN, Ruben; MACIEL, M. E.; BRUM, C. K (org.). Expressões da cultura gaúcha. Santa Maria: editora da UFSM, 2010.

ORTIZ, Renato. Estudos Culturais. Tempo Social, USP, São Paulo, p. 119-

127, julho de 2004. Disponível em: http://www.scielo.br/scielo.php?script =sci arttext\&pid $=$ S0103-20702004000100007. Acesso em: 10 abr. 2019. 
PEREZ GOMEZ. A. I. A cultura escolar na sociedade neoliberal. Porto Alegre: Artmed, 2001. p. 11-19.

PINHEIRO-MACHADO, Rosana. Precisamos falar sobre a vaidade na vida acadêmica. Carta Capital. 2016. Disponível em: https://www.cartacapital.com.br/sociedade/precisamos-falarsobre-a-vaidade-na-vida-academica/. Acesso em: 24 out. 2019.

PORTAL CAPES. [2014]. Disponível em: https://www.gov.br/capes/pt-br Acesso em: 30 maio 2014.

ROCKWELL, Elsie. La experiência etnográfica - Historia y cultura en los procesos educativos. Buenos Aires: Paidós, 2009.

ROSS, Paulo Ricardo. A crise da educação especial: uma reflexão políticae antropológica. Educ. Rev., Curitiba, n. 15, jan.-dez. 1999. Disponível em: http://dx.doi.org/10.1590/01044060.201. Acesso em: 19 de agosto de 2019

SANABRIA, Guillermo Vega. O ensino de antropologia no Brasil: um estudo sobre as formas institucionalizadas de transmissão da cultura. Dissertação de mestrado em Antropologia Social, UFSC., 2005. Disponível em: http://repositorio.ufsc.br/ handle/123456789/102383. Acesso em: 30 abr. 2021.

SERRES, Michel. Habiter. Paris: Le Pomier, 2011.

THIESSE, Anne-Marie. Ensinar a nação pela região: o exemplo da Terceira República francesa. Educação, [s.l.], v. 34, n. 1, Dossiê de Antropologia da Educação, p. 13-28, jan.-abr. 2009.

TOSTA, Sandra P.; ROCHA, Gilmar. Antropologia \& educação. Belo Horizonte: Autêntica, 2009.

TOSTA, Sandra; MAIA, Carla; SILVA, Weslei. Diálogos nas fronteiras: um estudo sobre educação e escola na antropologia brasileira. EDUR Educação em Revista, Belo Horizonte, v. 36, e222229, 2020.

\section{Ceres Karam Brum}

Doutora e professora do Departamento de Ciências Sociais da Universidade Federal de Santa Maria. Endereço profissional: Departamento de Ciências Sociais UFSM, Avenida Roraima, n. 1.000, CCSH II, prédio 74, $2^{\circ}$ andar, sala 221 , Campus Camobi, Santa Maria, RS. CEP: 97105-900.

E-mail: cereskb@terra.com.br

ORCID: https://orcid.org/0000-0001-6152-8616

\section{Como referenciar este artigo:}

BRUM, Ceres Karam. Aprendizados: uma reflexão sobre os lugares da Antropologia da Educação na formação de cientistas sociais. Ilha - Revista de Antropologia, Florianópolis, v. 24, n. 1, e80341, p. 95-116, janeiro de 2022. 